\title{
LOCAL INDIGENOUS GOVERNANCE DALAM MENINGKATKAN ECONOMIC GROWT DI KABUPATEN SIDOARJO
}

\section{LOCAL INDIGENOUS GOVERNANCE TO INCREASING ECONOMIC GROWTH IN SIDOARJO DISTRICT}

\author{
Dzakiyah Adalatul Hikmah, Aditama Azmy Musaddad S, Andre Prasetyo Utomo \\ Moch. Rozzaq, Fitra Adinia Rahmi \\ Ilmu Administrasi Negara, FISIP, UPN Veteran Jawa Timur \\ email: dzakiyahadalah@gmail.com, aditamaazmy@gmail.com, andreutomo1988@gmail.com, \\ rozzamoch926@gmail.com, adiniar27@gmail.com
}

\begin{abstract}
Abstrak
Lelang Bandeng adalah program unik dari Kabupaten Sidoarjo yang didasarkan pada perpaduan tradisi masyarakat pesisir dan nilai-nilai Islam tradisional. Program ini diadakan setiap tahun untuk memperingati Maulid Nabi Muhammad dengan tujuan utama meningkatkan pertumbuhan ekonomi dan religiusitas masyarakat. Lelang Bandeng merupakan bentuk local indigenous governance yang diprakarsai oleh Pemerintah Kabupaten Sidoarjo. Penelitian ini sangat penting dilakukan karena menggunakan frame analisis kebijakan publik dan belum pernah dilakukan sebelumnya. Tujuan dari penelitian ini adalah untuk menganalisis implementasi Lelang Bandeng, dan menjelaskan peran pemangku kebijakan. Metode yang digunakan dalam penelitian ini adalah deskriptif kualitatif dengan teknik pengumpulan data wawancara dan tinjauan pustaka. Hasil penelitian ini menunjukkan bahwa proses penerapan Bandeng Lelang Sidoarjo berjalan dengan baik dan dapat mendorong perekonomian masyarakat petani sekaligus meningkatkan religiusitas masyarakat. Meskipun beberapa hal perlu ditingkatkan, termasuk transparansi kegiatan anggaran, peran pemangku kepentingan tidak merata, sosialisasi program lemah. Program Lelang Bandeng layak digunakan sebagai referensi sebagai program pertumbuhan ekonomi berbasis masyarakat adat setempat.
\end{abstract}

Kata kunci: Analisis Kebijakan Publik; Lelang Bandeng; Local Indigenous Governance

\begin{abstract}
Lelang Bandeng is a unique program of Kabupaten Sidoarjo which is based on a blend of coastal community traditions and traditionalist Islamic values. This program is held every year to commemorate Maulid Nabi Muhammad with the main goal of increasing economic growth and community religiosity. Such as can be said that Lelang Bandeng is a form of local indigenous governance initiated by the Kabupaten Sidoarjo Government. This research is important to do because research on Lelang Bandeng with frames of analysis of public policy has never been done. The purpose of this research is to describe how the process of conducting Lelang Bandeng, implementation analysis Lelang Bandeng, and explains the role of policy stakeholders. The method used in this study is descriptive qualitative with interview data collection techniques and literature review. The results of this study indicate that the process of implementing Sidoarjo Lelang Bandeng is going well and can encourage the economy of the farmer community while increasing community religiosity. Although some things need to be improved, including the transparency of budget activities, the role of stakeholders is uneven, program
\end{abstract}


socialization is weak. Lelang Bandeng Program is worthy of being used as a reference as a local indigenous based economic growth program.

Keywords: Lelang Bandeng; Local Indigenous Governance; Public Policy Analysis

\section{Pendahuluan}

Kabupaten Sidoarjo merupakan salah satu wilayah pesisir di daerah Jawa Timur, sehingga memiliki potensi sumber daya alam yang kaya khususnya pada bidang kelautan dan pertambakan ikan. Kabupaten Sidoarjo menjadi salah satu daerah dengan luas tambak terbesar di Jawa Timur. Tercatat pada data Badan Pusat Statistik Sidoarjo (2003) Luas tambak Kabupaten Sidoajo sekitar 15.530 hektar dan memiliki jumlah petani tambak mencapai 3.227 orang. Hal ini menjadikan tambak sebagai sektor perikanan unggulan di Sidoarjo, khususnya komoditas bandeng.

Bandeng merupakan salah satu komiditi unggulan pemerintah Kabupaten Sidoarjo. Bandeng tergolong muda untuk dipelihara, karena bandeng memiliki toleransi hidup tinggi terhadap perbedaan salinitas air dan lingkungannya. Disisi lain, dipilihnya ikan bandeng sebagai salah satu komoditi utama dikarenakan bandeng tergolong jenis ikan yang paling banyak diproduksi dan sering dikonsumsi, serta menjadi salah satu komoditas ekspor para petani tambak yang konsisten dalam membudidayakan bandeng, sehingga hasil panen bandeng sangat melimpah. Hal ini tentu berpengaruh pada intensitas budidaya bandeng di Kabupaten Sidoarjo.

Budidaya bandeng yang ada di Sidoarjo memiliki peluang yang cukup besar untuk berkembang karena terdapat kesediaan lahan tambak yang luas. Industri pengolahan bandeng hampir selalu meningkat tiap tahunnya, kondisi ini diimbangi dengan permintaan bandeng yang cukup stabil. Hal ini disebabkan adanya kebiasaan dari masyarakat untuk menghidangkan bandeng sebagai salah satu sajian dalam hajatan tertentu, utamnya peringatan Maulid Nabi Muhammad. Peringatan Maulid Nabi Muhammad di Sidoarjo, bandeng menjadi menu yang khas untuk dihidangkan. Sehingga pada momen ini permintaan bandeng menjadi sangat tinggi, khususnya bandeng dengan ukuran besar atau yang biasa disebut bandeng kawak. Bandeng kawak adalah bandeng dengan berat diatas $4 \mathrm{Kg}$.

Adapun kondisi yang terjadi, pemerintah Kabupaten Sidoarjo berinisiatif untuk mengadakan kegiatan yang mewadahi tradisi tersebut, yakni lelang bandeng tradisional. Kegiatan ini diadakan agar masyarakat Sidoarjo dapat menyadari bahwa kekayaan alam tambak bandeng Sidoarjo sangat melimpah. Tujuan lainnya agar petani tambak termotivasi untuk meningkatkan kualitas tambaknya dan juga kualitas bandeng mereka.

Tradisi lelang bandeng tradisional diadakan rutin setiap satu tahun untuk memperingati maulid nabi. Lelang bandeng tradisional menunjukkan bahwa tradisi lokal yang diwadahi oleh pemerintah Kabupaten Sidoarjo dan dikembangkan dengan cara yang inovatif dapat memberikan manfaat secara sosial, ekonomi bagi masyarakat Sidoarjo. Menjadi hal yang penting diketahui serta dipahami bagi masyarakat agar tetap terjaga tradisi turun menurun tersebut. Program lelang bandeng tradisional 
mempunyai nilai-nilai yang penting yakni pelestarian tradisi lokal, perekonomian, sosial serta kolaborasi leading sector dalam pelaksaan lelang bandeng, sehingga patut untuk dibanggakan dan diperkenalkan serta diwariskan pada generasi selanjutnya di Sidoarjo.

Pelaksanaan lelang bandeng tradisional setiap tahun tak lepas dari upaya petani tambak dalam membudidayakan bandeng selama bertahun-tahun serta kolaborasi antar dinas dalam mewujudkan lelang bandeng tradisional. Lelang bandeng tradisional di Kabupaten Sidoarjo diadakan berbeda dengan proses pelelangan ikan pada umumnya. Perbedaan tersebut terdapat pada ukuran bandeng yang akan dilelang yakni diatas $4 \mathrm{~kg}$.

Berkaitan dengan paparan di atas program lelang bandeng tradisional merupakan bentuk local indigenous governance dalam memadukan konsep religi, konsep ekonomi dan konsep sosial yang memadukan kolaborasi dari 3 aktor/pilar governance. Konsep religi dalam lelang bandeng tradisional ini terselenggara karena wujud tradisi masyarakat pesisir dalam memperingati Maulid Nabi Muhammad SAW dan konsep ekonomi timbul karena adanya dorongan juragan tambak kepada petani tambak melakukan lelang bandeng untuk menghimpun hasil bandeng dan menambah pemasukan bagi petani tambak bandeng. Konsep Sosial juga terwujud dalam pelaksanaan lelang bandeng karena hasil dari perolehan lelang digunakan untuk kegiatan sosial yaitu untuk pembangunan masjid, musholla, gereja dan yayasan panti asuhan. Dari adanya perpaduan nilai tersebut kemudian diwadahi oleh goverment atau pemerintah daerah setempat untuk dijadikan kegiatan lelang bandeng setiap tahunnya.

Berdasarkan uraian di atas maka penelitian ini berfokus pada, analisis determinan implementasi lelang bandeng tradisional di Kabupaten Sidoarjo, dan kolaborasi peran dari actor governance (pemerintah / government, masyarakat / civilsociety, dan swasta / private) dalam lelang bandeng tradisional untuk meningkatkan economic growth di Kabupaten Sidoarjo. Penelitian ini di dasarkan pada beberapa landasan teori diantara lain :

\section{Implementansi Kebijakan Publik}

Kebijakan publik adalah segala hal yang dilakukan atau tidak dilakukan oleh pemerintah pusat/daerah maupun institusi yang berwenang. Menurut Thomas R Dye (1992) dalam Anggara (2014), "Public policy is whatever the government choose to do or not to do" dapat diartikan kebijakan publik adalah apapun pilihan pemerintah untuk melakukan sesuatu atau tidak melakukan sesuatu.

Model pendekatan implementasi kebijakan yang dirumuskan Van Meter dan Van Horn disebut dengan A Model of the Policy Implementation (1975). Model ini menjelaskan bahwa implementasi kebijakan berjalan secara linier dari keputusan politik, pelaksana bahwa kinerja kebijakan dipengaruhi oleh beberapa variabel-variabel tersebut yakni standar dan sasaran kebijakan/ukuran dan tujuan kebijakan, sumber daya, karakteristik organisasi pelaksana, sikap para pelaksana, komunikasi antar organisasi terkait dan kegiatan-kegiatan pelaksanaan serta lingkungan sosial, ekonomi, sosial dan politik. Adapun pemilihan teori ini bertujuan untuk mengetahui variabel- 
variabel yang menyebakan suatu keberhasilan dan kegagalan kebijakan. Analisa variabel-variabel yang ada dalam teori Van Metter dan Van Horn berkesinambungan dalam konteks Local Indigeneous Governance khususnya pelaksanaan lelang bandeng di Kabupaten Sidoarjo.

\section{Local Indigenous Governance}

Local Indigenous Governance adalah pemerintah berbasis kearifan lokal, pemerintah mengadopsi budaya/kearifan lokal dari daerah dalam penyelenggaraan birokrasi dan pelayanan publik. Menurut Siswadi, Taruna, \& Purnaweni (2012) Kearifan lokal yang dikonsepsikan sebagai pengetahuan setempat (local knowledge), kecerdasan setempat (local genius), dan kebijakan setempat (local wisdom), oleh UU RI No.32 Tahun 2009 tentang Perlindungan dan Pengelolaan Lingkungan Hidup dimaknai sebagai nilai-nilai luhur yang berlaku dalam tata kehidupan masyarakat yang antara lain dipakai untuk melindungi dan mengelola lingkungan hidup secara lestari.

Sedangkan menurut Christeward Alus (2014) Kearifan Lokal merupakan semua bentuk pengetahuan, keyakinan, pemahaman, atau wawasan serta adat kebiasaan atau norma yang menuntun perilaku manusia dalam kehidupan komunitas, ekologis. Kearifan lokal dapat dimaknai sebagai budaya masyarakat yang diturunkan turun-temurun dilingkungan masyarakat. Konsep Local Indigenous Governance termasuk dalam konsep Dynamic Governace.

\section{Dynamic Governance}

Dynamic Governance atau pemerintahan yang dinamis adalah pemerintahan yang berjalan secara dinamis sesuai dengan kondisi geopolitik, geoekonomi dan geososial yang ada di dalam masyarakat. Dalam buku Dynamic Governance (Neo, Boong Sion. Chen 2007) terdapat kapabilitas dinamis yang mempengaruhi pelaksanaan Dynamic Governance yakni : Thingking Ahead, Thingking Again, Thinking Across. Berpikir kedepan (Thingking Ahead) adalah kemampuan untuk mengidentifikasi perkembangan masa depan pada lingkungan, memahami implikasinya pada tujuan sosial-ekonomi yang penting, dan mengidentifikasi investasi strategis serta opsi yang diperlukan untuk memungkinkan masyarakat mengeksploitasi peluang baru dan menangani potensi ancaman. Berpikir lagi (Thinking Again) adalah kemampuan untuk menghadapi kenyataan saat ini mengenai kinerja strategi, kebijakan dan program yang ada, serta mendesain ulang mereka untuk mencapai kualitas dan hasil yang lebih baik. Berpikir menyeberang (Thinking Across) adalah kemampuan untuk melintasi batas-batas dan batas-batas tradisional untuk belajar dari pengalaman orang lain sehingga ide-ide bagus dapat diadopsi dan disesuaikan untuk memungkinkan kebijakan atau program baru dan inovatif untuk dicoba dan dilembagakan. Konsep pemerintahan yang dinamis dapat mempengaruhi kebijakan publik yang diambil, bentuk birokrasi dan pertumbuhan ekonomi.

\section{Economic Growth}


Economic Growth atau pertumbuhan ekonomi adalah peningkatan yang terjadi pada aspek ekonomi yang ada di masyarakat. Pertumbuhan ekonomi didasarkan pada sumber daya alam, sumber daya manusia, teknologi dan investasi yang berkembang di masyarakat. GDP (Gross Domestic Product) menjadi komponen dalam pertumbuhan ekonomi daerah dan GNP (Gross National Product) menjadi komponen dalam pertumbuhan ekonomi nasional. Menurut Haller (2012) Pertumbuhan ekonomi merupakan fenomena jangka panjang yang kompleks, serta mengalami kendala seperti: peningkatan populasi berlebihan, sumber daya yang terbatas, infrastruktur yang tidak memadai, pemanfaatan sumber daya yang tidak efisien, intervensi pemerintah yang berlebihan, model kelembagaan dan budaya yang membuat peningkatan itu sulit, dll. Lelang bandeng di Sidoarjo memberikan dampak perekonomian yang positif bagi masyarakat dan dampak pembangunan infrastruktur di Kabupaten Sidoarjo.

\section{Metode}

Penelitian ini adalah penelitian menggunakan pendekaan kualiatif. Menurut Masyhuri dan M. Zainudin (2009), Penelitan kualitatif adalah penelitian yang pemecahan masalahnya dapat menggunakan data empiris. Penelitian ini berlokasi di Dinas Perikanan dan Kelautan, Dinas Pendidikan dan Kebudayaan, Dinas Pemuda, Olahraga dan Pariwisata Kabupaten Sidoarjo yang telah dilaksanakan mulai bulan Juli - Agustus 2019. Adapun informan yang ada dalam penelitian ini adalah Kepala Bidang Usaha Perikanan, Dinas Perikanan Kabupaten Sidoarjo, Kepala Seksi Pemberdayaan Kesenian Rakyat Dinas Pendidikan dan Kebudayaan Kabupaten Sidoarjo dan Kepala Bidang Pariwisata Dinas Pemuda, Olahraga dan Pariwisata Kabupaten Sidoarjo. Teknik analisis data yang akan digunakan dalam penelitian ini adalah Interaktive model dari Miles dan Huberman. Pengumpulan data dalam penelitian ini menggunakan teknik wawancara dan pengumpulan dokumen dengan memperhatikan teknik triangulasi. Dalam penelitian kualitatif, kredibilias data yang diperoleh merupakan aspek yang sangat penting. Untuk itu diperlukan uji kredibilitas data, dalam penelitian ini digunakan teknik triangulasi. Triangulasi adalah teknik uji kredibilitas yang mana dalam teknik ini dilakukan serangkaian uji silang dari berbagai sumber data, berbagai teknik pengumpulan data dan lintas waktu.

\section{Hasil dan Pembahasan}

\section{Analisis Implementasi Lelang Bandeng Tradisional}

Analisis pelaksanaan lelang bandeng menggunakan model teori implementasi kebijakan van meter dan van horn, terdapat 6 variabel-variabel yang mempengaruhi yaitu :

1. Ukuran dan tujuan kebijakan

Lelang bandeng tradisional merupakan kegiatan yang telah dilaksanakan secara turun temurun, lelang bandeng pertama kali dilaksanakan pada hari rabu tanggal 18 juli tahun 1962 oleh 
pemerintah Kabupaten daerah tingkat II Sidoarjo. Adapun tujuan diadakannya Lelang bandeng kawak ialah a) Melestarikan seni budaya dan Tradisi lelang bandeng kawak. b) Memberikan motivasi bagi pembudidaya bandeng kawak. c) Menggugah kebersamaan antara Pemerintah dengan masyarakat terutama para pengusaha tambak.

Pelestarian seni budaya dan tradisi lelang bandeng kawak perlu dilakukan oleh pemerintah kabupaten sidoarjo, mengingat potensi dari acara tersebut dapat dijadikan obyek wisata unggulan, selain itu dana perolehan lelang bandeng kawak dapat menunjang kegiatan sosial pemerintah kabupaten sidoarjo. Pada tahun 2017 lelang bandeng kawak berhasil mengumpulkan dana sebesar 2 miliar, perolehan dana hasil lelang bandeng kawak tersebut selanjutnya dialokasikan untuk kegiatan sosial seperti pembangunan dan perbaikan rumah ibadah.

Petani tambak memerlukan waktu 7 tahun untuk dapat memperoleh bandeng kawak seberat 5 $\mathrm{Kg}$. Dinas perikanan mengklasifikasikan hanya bandeng dengan berat minimum $5 \mathrm{Kg}$ yang dapat menjadi peserta lelang bandeng tradisional kawak. Lamanya proses pemeliharaan bandeng kawak, membuat pemerintah Kabupaten Sidoarjo memberikan perhatian dan motivasi lebih untuk pembudidaya bandeng kawak. Adapun standar kebijkan tertuang jelas dalam petunjuk pelaksanaan dan petunjuk teknis pelaksanaan lelang bandeng Kabupaten Sidoarjo.

2. Sumber daya

Keberhasilam implementasi kegiatan lelang bandeng tradisional bergantung kepada aspek memanfaatkan sumber daya manusia. Selain sumber daya manusia, terdapat pula sumber daya finansial dan waktu yang menjadi perhitungan penting dalam implementasi kebijakan lelang bandeng tradisional.Sumber daya manusia atau panitia kegiatan lelang bandeng tradisional diketuai oleh wakil bupati sidoarjo dan diawasi bupati Sidoarjo yakni H.Saifullah yang juga merupakan ketua Forum Komunikasi Masyarakat Tambak (FKMT) dan beberapa dinas yang terlibat menjadi panitia. Penyelenggaraan lelang bandeng tradisional didukung oleh pemerintah kabupaten sidoarjo menggunakan dana Anggaran Pendapatan dan Belanja Daerah ( APBD ) untuk penyediaan hadiah bagi pemenang, pelaksanan festival, perlengkapan setiap rangkaian festival dan bintang tamu di malam puncak yaitu pada saat lelang bandeng dilaksanakan. Sumber daya fasilitas yang diperlukan seperti penginapan, makanan, transportasi, kostum dan perlengkapan yang menunjang pelaksanaan acara.

3. Karakteristik Organisaisi Pelaksana

Pelibatan beberapa dinas pemerintahan menunjukkan luasnya cakupan kebijakan lelang bandeng tradisional. Agen pelaksana dengan karakteristik yang berbeda akan berdampak pada keberhasilan implementasi kebijakan. Dinas perikanan merupakan sektor yang paling berpengaruh, Karena proses pelaksanaan lelang bandeng yang menjadi inti acara tidak dapat terselenggara apabila pelaksanaan survey kepada petani tambak bandeng kawak tidak dilakukan. Tentu diperlukan kolaborasi antar sektor kedinasan untuk mendukung implementasi kebijakan festival lelang badeng, 
hal ini ditunjukan dengan padatnya rangkaian acara lelang bandeng tradisional, seperti ; pasar bandeng murah, kirab bandeng kawak, timbang bandeng kawak, pelelangan bandeng kawak, pembacaan diba', lomba-lomba dan pemberian bantuan/ santunan.

Event Organizer juga dilibatkan dalam pelaksanaan lelang bandeng tradisional, duta pariwisata gus dan yuk kabupaten sidoarjo dilibatkan guna menarik kalangan remaja sidoarjo untuk datang selama rangkaian lelang bandeng tradisional kawak, selain itu terdapat forum komunikasi masyarakat tambak yang turut mengambil peran dalam rangkaian acara lelang bandeng tradisional kawak. Agen pelaksana yang terlibat meliputi organisasi formal dan organisasi informal, hal ini menunjukkan luasnya cakupan implementasi kebijakan lelang bandeng tradisional di kabupaten sidoarjo.

\section{Sikap pelaksana}

Pelaksanaan Lelang bandeng tradisional melibatkan sektor pemerintahan, organisasi masyarakat dan swasta. Agen pelaksana menjadikan lelang bandeng tradisional sebagai motivasi untuk terus memberikan inovasi - inovasi dalam setiap rangkaian acara karena lelang bandeng tradisional merupakan suatu seni budaya dan tradisi yang harus tetap dilestarikan. Agen pelaksana mendukung penuh terselenggaranya lelang bandeng tradisional, kolaborasi antar dinas dan diketua oleh wakil bupati menjadikan tugas yang diemban oleh dinas terkait menjadi lebih ringan, karena tugas, pokok dan fungsi setiap dinas telah terbagi. Evaluasi pasca acara bertujuan untuk mengetahui kekurangan dari setiap rangkaian acara dan untuk tahun berikutnya akan dijadikan bentuk perencanaan baru, hal ini untuk menghindari titik jenuh masyarakat dan wisatawan dalam menyaksikan rangkaian kegiatan lelang bandeng tradisional kawak.

\section{Komunikasi Antar Organisasi dan Aktivitas Pelaksana}

Proses penyampaian informasi dari atas ke bawah seringkali mengalami distorsi, baik disengaja ataupun tidak disengaja, upaya preventif yang dilakukan untuk distorsi informasi, adalah menempatkan bupati sebagai pengarah, dan wakil bupati sebagai ketua pelaksana kegiatan lelang bandeng tradisional. Peran bupati yang juga menjabat sebagai ketua FKMT, menjadikan arus informasi yang diterima dapat diperoleh dari berbagai pihak, dan apabila terdapat informasi yang tidak sesuai dengan apa yang direncakan, dapat langsung diatasi dengan memberikan arahan atau terjun langsung kepada pihak pelaksana. Proses pelaksanaan komunikasi dan koordinasi yang telah dilakukan dengan baik, akan memberikan dampak yang besar dalam pengimplementasian kebijakan publik karena asumsi - asumsi kesalahan akan sangat kecil terjadi, dan apabila ada, akan sangat mudah diatasi karena pola komunikasi dan koordinasi telah dilakukan dengan baik.

6.Lingkungan Ekonomi, Sosial, dan Politik

Lingkungan ekonomi, sosial dan politik seringkali menjadi faktor eksternal yang menghambat dan menggagalkan kinerja implementasi kebijakan publik. Tinjauan mengenai lingkungan ekonomi, sosial dan politik dalam implementasi kebijakan publik lelang bandeng tradisional, peneliti tidak 
menemukan permasalahan eksternal dan internal yang dapat menghambat dan menjadi faktor kegagalan implementasi kebijakan festival lelang bendeng. Seluruh aspek mendukung adanya pelakasanaan guna melestarikan tradisi dan seni budaya kebanggaan masyarakat dan pemerintah kabupaten sidoarjo.

Dari analisis implementasi diatas menujukkan bahwa terdapat faktor yang mempengaruhi pelaksanaan lelang bandeng tradisional Kabupaten Sidoarjo. Adapun faktor - faktor yang memperngaruhi yaitu faktor pendorong dan faktor penghambat. Faktor pendorong pelaksanaan lelang bandeng yaitu sumber dana APBD yang mencukupi, sumber daya manusia yang handal, kolaborasi antar dinas yang baik, kebudayaan masyarakat sidoarjo yang kental dengan tradisi lelang bandeng dan fakto penghambat yaitu terdapat kegiatan/program dari dinas yang berkolaborasi melaksanakan program lelang bandeng, menurunnya minat pengusaha untuk turut terlibat dalam lelang bandeng, menurunnya minat anak muda untuk melihat lelang bandeng tradisional.

2. Kolaborasi Peran Actor Governance (pemerintah/government, masyarakat/ civil society, dan swasta/private) dalam lelang bandeng tradisional untuk meningkatkan economic growth di Kabupaten Sidoarjo

Dalam pemerintah yang governance dituntu sinergi diantara ke tiga pilar governance menurut Santoso (2008) dalam Anggara (2018) yaitu 1) Pemerintah, 2) Masyarakat (community/civil society/ masyarakat madani), 3) Pihak swasta (private). Komunikasi antar organisasi pelaksana dilakuan dengan rapat koordinasi yang dipimpin oleh wakil bupati selaku ketua pelaksana. Rapat koordinasi menuju acara lelang bandeng membutuhkan waktu kurang lebih selama 1 bulan dilanjutkan dengan pembagian tugas tiap stakeholder agar lebih optimal. stakeholder tersebut antara lain 1) Dinas Perikanan Kab. Sidoarjo sebagai mediator petani-petani bandeng dalam event ini serta melakukan seleksi terhadap kriteria bandeng yang dapat mengikuti lelang, selain itu dinas perikanan bertanggung jawab atas pembinaan FKMT ( Forum Kesejahteraan Masyarakat Tambak ) di Sidoarjo sehingga Dinas Perikanan ini berfungsi sebagai pelaksana teknis festival lelang bandeng 2) Dinas Kepemudaan, Olahraga dan Pariwisata Kab. Sidorajo sebagai promotor dalam event ini dan melakukan pembinaan pada Duta Wisata Guk \& Yuk Sidoarjo untuk lebih giat mempromosikan program ini menjelang acara berjalan. 3) Dinas Pendidikan dan Kebudayaan Kab. Sidoarjo sebagai penyusun acara dan sub kegiatan yang terdapat dalam Lelang Bandeng Sidoarjo. Dinas ini juga bertanggung jawab atas pengelolaan dana hadiah dan pembinaan pada sanggar tari di Sidoarjo untuk menyajikan tampilan yang maksimal saat acara berlangsung. Kegiatan lelang bandeng juga dibantu oleh 4) Koperasi Sidoarjo sebagai pengadaan Bazar UMKM yang dilakukan pra acara lelang bandeng. 5) Dinas Kominfo yang mengatur siaran radio sebagai media promosi, 6) Dinas Perijinan bertugas mengundang pengusaha dari dalam maupun luar kota untuk turut memeriahkan Lelang Bandeng. Adapun pihak swasta diundang pada malam puncak lelang bandeng tradisional untuk menawar pada proses lelang bandeng. Pihak swasta menentukan besarnya nilai dana yang 
terkumpul, hal ini berdampak pada nilai ekonomi yaitu pemasukan bagi dana Kabupaten Sidoarjo Disisi lain masyarakat Kabupaten Sidoarjo atau luar Kabupaten Sidoarjo berperan sebagai penikmat dan pengunjung serangkaian acara lelang bandeng tradisional Kabupaten Sidoarjo. Adapun perolehan dana hasil lelang bandeng dapat dilihat pada

Tabel 1

Perolehan Hasil Bandeng Tahun 2015-2019

\begin{tabular}{ll}
\hline Tahun & Perolehan Dana \\
\hline 2019 & Rp. 700.000 .000 \\
\hline 2017 & Rp. 2.000 .000 .000 \\
\hline 2016 & Rp. 1.300 .000 .000 \\
\hline 2015 & Rp. 1.500 .000 .000 \\
\hline
\end{tabular}

Sumber : Diolah dari Detik News 2019, Liputan 6 2017, Bangsaonline 2016, Tribunnews 2015.

Dalam segi peningkatan ekonomi di Kabupaten Sidoarjo terwujud melalui lelang bandeng tradisional yaitu dengan adanya pasar murah dan stand bazar UMKM di alun-alun Sidoarjo. Lelang Bandeng tradisional membuka kesempatan bagi pedang yang berjualan disana sehingga dapat memenuhi kebutuhan hidup. Hasil dana dari lelang yang telah ditawar oleh pihak swasta menghasilkan pemasukan bagi pemerintah kabupaten Sidoarjo, hasil dana tersebut dihimpun oleh badan keuangan Sidoarjo dan akan digunakan untuk kegiatan pembangunan rumah dan kepentingan sosial masyarakat.

Dalam implemetasi kegiatan lelang bandeng dikatakan berhasil dan suskses menggelar event setiap tahunnya, meskipun dalam pelaksanaannya belum maksimal. Adapun pelaksanaan pada tahun 2018 bupati wakil bupati, dan dinas terkait sepakat tidak melaksanakan lelang bandeng dikarenakan waktu maulid nabi yang berdekatan menyebabkan pemerintah daerah sepakat menjalankan dua kali pelaksanaan lelang bandeng pada tahun 2019 yaitu pada bulan januari dan november. Dari data hasil lelang bandeng pada tahun 2016 terus mengalami peningkatan hingga tahun 2017 mencapai 2 Milliar. Tetapi mengalami penurunan pada tahun 2019 sehingga perlu adanya inovasi kegiatan dan publikasi lebih menyeluruh dari dinas-dinas penyelenggara kegiatan untuk menarik minat pihak swasta dan masyarakat untuk hadir dalam rangkaian acara lelang bandeng.

Rangkaian acara lelang bandeng belum mendapatkan respon yang baik bagi masyarakat Sidoarjo sendiri karena masih banyak masyarakat yang belum mengetahui event lelang bandeng ini khususnya generasi muda. Lelang bandeng merupakan bentuk tradisi yang harus dilestarikan masyarakat Sidoarjo sehingga perlu adanya publikasi lebih intensif baik kepada masyarakat Sidoarjo atau luar Sidoarjo. Serangkaian acara lelang bandeng memberikan dampak positif bagi masyarakat Sidoarjo yaitu meningkatkan perekonomian daerah Sidoarjo itu sendiri khususnya warga kabuaten Sidoarjo. 
Dampak kebijakan pemerintah memberikan wadah bagi petani tambak untuk melakukan lelang bandeng memberikan dampak bagi kesejahteraan petani tambak yang telak membesarkan bandeng kawak, penjual bandeng pada pasar murah, menyediakan wadah bagi pedang UMKM dalam bazar di Alun-Alun Sidoarjo, serta dana hasil lelang tersebut dihimpun untuk digunakan untuk kegiatan pembangunan rumah dan kepentingan sosial masyarakat.

\section{Penutup}

Lelang Bandeng sebagai local indegeous governance memiliki nilai religious, ekonomi, dan sosial sehingga memberikan pengaruh yang signifikan terhadap economic growth warga melalui Pemerintah Kabupaten Sidoarjo sebagai konseptor dan perencana strategis yang merupakan komponen penting, peran sertanya menjadi bukti bahwa Kabupaten Sidoarjo berkomitmen untuk mempertahankan nilai-nilai kearifan lokalnya.

Berdasarkan teori implementasi Van Meter dan Van kegiatan Lelang Bandeng telah memenuhi 6 variabel determinan teori implementasi Van Meter dan Van Horn. Namun dalam pelaksanaannya masih belum maksimal karena belum terdapat adanya transparansi dana pengelolaan hasil Lelang Bandeng pada masyarakat serta promosi kegiatan yang belum merata terhadap masyarakat luas Kabupaten Sidoarjo.

Ketiga pilar good governance yaitu government, civil society, dan private sector mampu menunjukkan kolaborasi yang selaras terbukti dengan adanya pembagian yang tersusun rapi dan terstruktur dengan baik melalui tata kelola menajemen. Government (Pemerintah Daerah) sebagai pelaksana kegiatan, Private Sector selaku penawar Lelang Bandeng, Civil Society pengunjung kegiaatan Lelang Bandeng. Sebagai peneliti, kami merekomendasikan beberapa hal terkait hasil penelitian yang telah dilakukan kepada pemerintah daerah dan dinas-dinas terkait, antara lain :

1. Pemerintah Kabupaten Sidoarjo harus lebih transparan terhadap dana hasil lelang karena akan berpengaruh kepada tingkat kepercayaan masyarakat terhadap pemerintah atau aktor pelaksana, selain itu masyarakat dapat mengetahui jumlah dana yang dikeluarkan untuk bantuan sosial.

2. Minimnya minat generasi muda dalam acara lelang bandeng tradisional menyebabkan perlunya pelibatkan peran pemuda-pemudi Sidoarjo guna meningkatkan pengetahuan dan branding Lelang Bandeng Tradisional. Publikasi/promosi lebih digiatkan dapat melalui pamflet, brosur, media online ke masyarakat khususnya di desa-desa yang jauh dari daerah pesisir, masyarakat yang belum mengetahui pelaksanaan kegiatan Lelang Bandeng.

3. Kolaborasi actor governance (pemerintah/government, masyarakat/civil society, dan swasta/private) dalam lelang bandeng tradisional pada daerah pesisir dapat meningkatkan perekenomian masyarakat sekitar dan konsep kegiatan ini layak menjadi percontohan bagi daerah pesisir yang ada di Indonesia. 


\section{Referensi}

Anggara, Sahya. 2018. Kebijakan Publik. 2 ed. Bandung: Pustaka Setia.

Badan Pusat Statistik Kabupaten Sidoarjo. 2003. Kabupaten Sidoarjo Dalam Angka.

Christeward Alus. 2014. "Peran Lembaga Adat Dalam Pelestarian Kearifan Lokal Suku Sahu

Di Desa Balisoan Kecamatan Sahu Kabupaten Halmahera Barat.” Acta Diurna III(4):1-16.

Haller, Alina-petronela. 2012. "Concepts of Economic Growth and Development. Challenges of Crisis and of Knowledge.” Economic 15(1):66-71.

Keputusan Bupati Sidoarjo nomor : 188/438.1.3.3/2019 tentang Panitia Penyelenggara Lelang Bandeng Tradisional Kabupaten sidoarjo tahun 2019

Kurniawan, D. (2017). Laris Manis 4 Bandeng Kawak Seharga Rp. 2 Miliar. Liputan 6. Agustust $25,2019.07: 31$

Masyhuri dan M. Zainuddin. (2009). Metodologi Penelitian Sosial dan Ekonomi, Teori dan Aplikasi. Penerbit Alfabeta. Bandung

Mustain. (2017). Raup 1,3 Miliar Rupiah, Lelang Bandeng Kawak Sidoarjo Diharapkan TembusInternasional. BangsaOnline. Agustust 30, 2019. 17.30

Neo, Boong Sion. Chen, Geraldine. 2007. DYNAMIC GOVERNANCE. First. Singapore: Word Scientific Publishing Co. Pte. Ltd 5 Toh Tuck Link, Singapore 596224.

Siswadi, S., Tukiman Taruna, dan Hartuti Purnaweni. 2012. "KEARIFAN LOKAL DALAM MELESTARIKAN MATA AIR (Studi Kasus di Desa Purwogondo, Kecamatan Boja, Kabupaten Kendal)." Jurnal Ilmu Lingkungan 9(2):63.

Taufik, M., \& Iskandar, E. Y. (2019). Lelang Bandeng di Alun-alun Sidoarjo Kumpulkan dana Rp 700 juta. Jatim TribunNews.. Agustust 28, 2019. 15:30

UU RI No.32 Tahun 2009 tentangPerlindungan dan Pengelolaan Lingkungan Hidup

Van Meter, S. D., \& Van Horn, C. (1975). The Policy Implementation Process:

A Conceptual Framework. Administration \& Society, 6(4), 445. 